\title{
Online Marketers Beware: M-Commerce is changing Your Game
}

\author{
Ms. Neha Sagar \\ Assistant Professor University Of Delhi
}

\begin{abstract}
M$-Commerce is a subset of E-commerce which includes all e-commerce transactions carried out using a mobile device. M-commerce is a major application domain for mobile devices, enabling users to perform commercial transactions wherever they go. As the power of wireless increases, it provides various opportunities for improving services to customers. In today's era, mobile commerce or M-Commerce has entered almost all the aspects of Business organizations like finance, retails, services, telecommunications and information technology services. This paper discusses the concept of Mobile Commerce. It looks at how the technology of Mobile Commerce has facilitated new business trends. After this there is detailed description of applications of M-Commerce, its advantages \& disadvantages. In last finally it throws light on the challenges that are faced by $M$-Commerce.
\end{abstract}

Keywords: M-Commerce, Applicability, Challenges, Growth, Consumer accessibility to internet.

\section{Introduction}

M-commerce or mobile commerce refers to the conducting of buying and selling of googs and services through internet-enabled mobile devices. M-commerce enables users to access users to access internet without needing to find a place to plug in. M-Commerce, also known as Mobile Commerce, is the ability of buying and selling goods and services through the use of mobile devices like Cellular Telephone, tab and PDA's. It is also known as next generation. E-Commerce that needs no wire and plug in devices. "Mobile Commerce refers to any transaction with monetary value that is conducted via a mobile telecommunications network." Mobile phones impose different constraints than desktop computers. But they also open the door to a treasure of new applications and services. They follow you wherever you go, making it possible to look for a nearby cafeterias, stay in touch with friends, or pay for the items. So the mobility is the primary driving force behind mobile commerce, or m-commerce. With the rapid increase in Smartphone access across the globe, mobile commerce has gained increasing acceptance by the users. Mobile Commerce is completely different from overall mobility and mobile applications as it provides customers with the ability to buy products by using mobile devices. Despite of huge popularity of mobile commerce, it is yet in the preliminary stage and can be further develop in all the fields, which can affect the human life.

According to Webagency,2001. "Mobile Commerce is the use of information technologies and communication technologies for the purpose of mobile integration of different value chains and business processes and for the purpose of management of business relationships". M-commerce became possible with the integration of the mobile phone and the internet.

\section{APPLICABILITY OF M-COMMERCE}

Mobile Commerce has gained increasing reception amongst various sections of society in the last few years. Mobile services have registered remarkable growth in past years and M-Commerce is slowly but surely showing signs of a healthy growth. Following are the some of the applications of M-Commerce:

* Entertainment-- Entertainment has always played a crucial role in Internet applications and is probably the most popular application for youth. Mobile commerce makes it possible to download games, images, music, video files at anytime and anywhere, and it also makes on-line games much easier to access and play.

* Mobile Ticketing- M-Commerce facilitates Mobile Ticketing. By this user is able to use their tickets immediately by presenting their phones at the venue. By utilizing the B CODE technology or NFC1 technology we could use the mobile phone as a means of receiving E-Tickets. B CODE technology consists of sending text SMS which is scan able from the mobile phone display screen through the related set. So by receiving the chosen SMS, the ticket is practically received and we could present the mobile phone to the scanning machine at the ticket receipt spot.

* Location Based Services- Mobile Commerce transactions also provide location based services. These include-

- Local Offers

- Local Maps 
- $\quad$ People Tracking and

- Monitoring Local Weather

* Inventory Tracking and Dispatching: Today Just-in-time delivery is the utmost requirement for the success of any business. Mobile commerce allows a business to

keep track of its mobile inventory and make time-definite deliveries, thus enhancing customer service, decreasing inventory and improving a company's competitive edge.

* Mobile Banking- Banks and other financial institutions influence the use of M-commerce by allowing the customers not only to access the account information, but

also facilitates other transactions like purchasing stocks, paying the bills, remitting money via mobile phones and other mobile devices.

* Health Care: M-Commerce can help to reduce the high cost of health care. By using the technology of mCommerce, physicians and nurses can remotely access and update patient records immediately. This improves productivity and efficiency, reduces clerical overheads, and enhances service quality. Mobile technologies such

as PDAs, Laptops or Tablet PCs can be of great value in hospitals and healthcare facilities by allowing better access to critical information.

* Traffic: The passengers in the vehicles and the pedestrians all are mobile objects, ideal clients of mobile commerce. Also, traffic control is usually a major problem for many metropolitan areas. Using the technology of mCommerce, the flow of traffic can be improved in many ways. For example, a mobile handheld device ,having the capabilities of a GPS, can determine the driver's exact position, giving directions, and advising on the current status of traffic in the area. A traffic control center could also monitor and control the traffic according to the signals sent from mobile devices in the vehicles.

* Commerce: Commerce is the exchange or buying and selling of merchandise on a large scale involving the transportation of goods from one place to another. It is enhanced by the convenience and ubiquity conveyed by mobile commerce technology. For example, mobile users can check their bank accounts and perform account balance transfers without needing to go to a bank, consumers can reserve the tickets or pay bills fee by using their mobile phones.

* Enterprise Resource Planning (ERP): In the coming mobile commerce era, users will be able to have access to the right resources and work as efficiently as possible whether they are travelling, meeting a customer or working at some remote location with their ERP systems. Many ERP vendors are currently researching for means to provide mobility to ERP users. They attempt to connect employees to their work more effectively than ever before by enabling mobile phones and other wireless devices to become a new kind of tool to flawlessly exchange information, automate data entry and perform various transactions anywhere, anytime.

In short, Main WAP applications are as follows:

\begin{tabular}{|c|c|}
\hline For Companies & r Consumers \\
\hline $\begin{array}{ll}\text { - } & \text { Corporate e mail } \\
\text { - } & \text { File Transfer } \\
\text { - } & \text { Job Dispatch } \\
\text { - } & \text { Rensumer Service } \\
\text { - } & \text { Meter Reading } \\
\text { - } & \text { Vehicle Positioning } \\
\text { - } & \text { Web Browsing } \\
\text { - } & \text { Documents sharing } \\
\text { - } & \text { Remote LAN access } \\
\text { - } & \text { Still and Moving Images } \\
\text { - } & \text { Home automation } \\
\end{array}$ & $\begin{array}{l}\text { Mobile Banking } \\
\text { Prepayment } \\
\text { Unified Messaging } \\
\text { Voice and fax mail } \\
\text { Affinity programs } \\
\text { Internet E-mail } \\
\text { Information service } \\
\text { Chat } \\
\text { Ringtones }\end{array}$ \\
\hline
\end{tabular}

\section{Benefits Of M-Commerce}

The use of E-commerce is provided only when the user is at his/her own home or workplace or in any other location where he/she can access media such as Internet or TV while M-commerce merely need the Mobilephone. However this doesn't mean that M-commerce is limited to ordinary applications like reading E-mail or reporting. Below are some of the advantages of M-commerce:

1. Increase efficiency.

2. Decrease transaction cost. 
3. Flexible Accessibility.

4. Simplify Business Processes.

5. Spontaneous decisions.

6. Location and Time Independent.

7. Reduce time consumption.

8. Providing wider reach.

9. Much Convenient.

10. Personally owned smart phones reduce IT training.

11. Online banking

\section{LIMITING FACTORS OF M-COMMERCE}

Besides all the above mentioned advantages, M-Commerce has the following limitations:

1. Lack of Standards.

2. Weak processors.

3. Limited memory.

4. Small screens poor resolutions.

5. WAP and SMS limited to small numbers of characters and text.

6. Limited graphics.

7. Less functionality for mobile internet over mobile phones and existing generation of mobile computers.

handhelds than for

8. Difficult to learn User Interface.

9. Limited Bandwidth.

10. Cost of establishing mobile and wireless broadband infrastructure.

11. Security of data moved across some mobile and wireless networks.

12. Poor data entry.

13. Health problems- microwaves can cause damage to DNA.

14. Addiction in teenagers.

\section{CHALLENGES FACED IN M-COMMERCE}

Though M-Commerce is blessing for everyone, but there are some challenges to it as well. The high prices of mobile services together with the slow access speed have not helped to add to the shine of the mobile environment. Some of the key challenges are as discussed below.

* Lack of Awareness - Comparatively there is less consumer awareness regarding the value of MCommerce, because currently only a few M-Commerce application are existing, although the number has begun to increase.

* Security Problems- The biggest worry of a user is the safety and reliability of business transactions over a wireless connection. Users will engage in mCommerce only if they trust that the transactions made through their devices are secure. Security of data transmissions and commerce being conducted by wireless devices is a great concern for businesses and individuals today. A prerequisite for the success of M-Commerce applications is the legal recognition and non disputability of any transactions. The mobile digital signature can resolve this problem.New smart cards, available for wireless communications applications, will enable secure transactions via the Internet. The wireless identity module (WIM) will guarantee a new level of security by giving mobile Internet users the ability to safeguard their transactions through encryption and digital signatures. The card offers two forms of protection: client-to-server authentication using ultra long keys, and the ability to generate the digital signature required to secure the application. One of the advantages of smart card IDs is that they are extremely hard to copy. To crack a private key stored in a smart card or guess its value based on a corresponding public key is very difficult. A PIN code is added as an extra security measure to avoid abuse if the card gets stolen or lost. An ordinary ID card can only be used for identification, while a smart-card-based ID card can also be used to digitally sign documents and transactions in a non repudiated way. However, the security measures typically implemented with a wireless application delivery approach can add to the costs and make the computing system more complex to administer and use.

* Lack of Simple and Standardized Payment Mechanism- There is no equivalent of the Credit Card or ATM offering an easy way to make payments through mobile phones in India. But many countries like USA and Japan have developed Mobile Payments which directly increase the use of M-Commerce.

* Distortion between Service Providers and Network Operators - On the Internet, any provider who confirms to the Net's standards can put an application online without anyone's permission- on mobile 
networks, providers have to work with private network operators. At present, there are many small service providers who must depend on a relatively few large mobile network operators to reach customers. Because of this imbalance, the operators capture the biggest share of the revenues generated by value-added services.

* Diverse Atmosphere- The most crucial challenge for service providers is that they must develop applications for multiple networks and a wide range of devices. According to Vanu Bose, chief executive officer (CEO) of Vanu Inc., whereas there are only two major Web browsers for PCs, in the world of mobile phones there are multiple operating systems with multiple browsers, so that same application can look

completely different on different screens. As we know, without standardization developing m-commerce applications can be unaffordable for the customers.

* Wireless Constraints--Developing content for wireless devices requires rethinking the Web experience. Wireless content developers need to begin from the ground up, developing content for these new devices. Wireless devices also tend to be monochromatic, so images do not render well. Keyboards are difficult to use. Wireless devices tend to have limited CPU, memory, and battery life. Developers and designers need to find new, intuitive navigational techniques to overcome these constraints. Content developers need to develop with these motives in mind. Rather than just translating a content-rich site into WML, developers need to think in terms of surgical access to content and drilling-down capabilities to detailed information in the site.

* Wireless User Behaviour--Wireless users will not be expected to "surf the Web" in the traditional sense. This is due to the viewing and input constraints of using a wireless device and the relative inconvenience of performing any but the most straightforward, time-critical tasks. More likely, wireless users are expected to use their devices to execute small, specific tasks that they can take care of quickly, such as finding the time of local events, purchasing tickets, looking up news, or checking e-mail.

* Infrastructure for Wireless Internet--Currently, the infrastructure to handle smart cards is not generally established. Most industry analysts believe that smart cards will eventually become main stream for paying in shops and on the Internet, together with a PC. In many countries, smart ID cards will also become fairly wide-spread. One of the problems is that the cost for shops, banks, companies, homes, and PC owners to convert to smart cards makes the process fairly slow.

* Privacy--Privacy is another issue not resolved by the growth of m-commerce. The new connectivity of consumers to the Internet is a great convenience for consumers, but it also comes at a price. The price is the value of privacy that individuals lose, as they become hooked-up to the Internet. One part of privacy is that the development of smart cards for use with cell phones is convenient for consumers wanting to buy or sell. However, much personal data is enclosed on the card, and it could be used for the wrong purposes. Many cell phones can be equipped with a global positioning chip that can identify the location of the user. This new technology would be good for emergencies but could also be used against the individual for monitoring purposes or other activities. These are issues that still need to be addressed and have been downplayed by current technology developers. Privacy is one of several issues that complicate the long-term timetable for developing location-based m-commerce.

\section{Growth And Future Outlook Of M-Commerce}

Some applications of m-commerce will become popular. These are time-critical services that people would need on their way e.g traffic news, stock market reports booking function etc.

In order to exploit the M-commerce market potential, handset manufacturers such as Nokia, Ericsson, Motorola, and Qualcomm are working with carriers such as AT \& T Wireless and sprint to develop WAP enabled smart phones.

As content delivery over wireless device become faster, more secure, and scalable there is wide speculation that it will surpass wireline E-commerce as the method of choice for digital commerce transactions. The industries affected by M-commerce include:

- Financial Services, which includes mobile banking as well as brokerage services in which stock quotes can be displayed and trading conducted by the same handheld device. 
- Telecommunications, in which service changes, bill payment and account reviews can all be conducted from the same handheld device.

- Service/retail, as customers are given the ability to place and pay for orders on-the-fly.

- Information Services which include the delivery of financial news, reports, figures and traffic updates etc.

There are two possible directions for the development of M-commerce in near future:

- M-commerce becomes the next hype-with all the consequences of a hype.

- M-commerce is a natural evolution from M-commerce into a digital and mobile world.

\section{New report highlights growth of mobile sector}

Leading market research firm yStats has released a new report concerning the global mobile commerce sector. The report, aptly named "Global Mobile and M-Commerce Report 2012," highlights the growth that the mobile commerce sector had seen throughout the entirety of 2012 and what this growth could mean for the future. The mobile space has been gaining a significant amount of attention from businesses and consumers alike and many have been gravitating toward the new form of commerce that has emerged thanks to the advent of new technology.

\section{MOBILE SALES RISE THROUGHOUT 2012}

According to the report, the global mobile commerce sector saw impressive growth during 2012. In the U.S., mobile sales grow significant faster than regular online sales throughout 2012, especially when it came to purchasing tickets for sporting events and general travel. Beyond the U.S., the United Kingdom has establish a significant degree of momentum in the mobile commerce space and is expected to lead Europe in terms of total mobile and online sales thanks to the progress it has seen in this sector in 2012.

\section{Mobile shoppers to reach 600 million by 2014}

The number of mobile shoppers throughout the world is expected to reach beyond 600 million by 2014 . Many consumers are beginning to show more interest in shopping from their mobile devices than through other platforms. Some are even opting to avoid physical stores in favour of mobile shopping. This is partly due to the convenience that mobile commerce represents as well as the growing availability of secure and comprehensive mobile payment services that align with the interests of consumers.

Retailers continue to show strong interest in mobile commerce

Retailers see a great deal of promise in the mobile sector and many companies have been working to become more accommodating to mobile shoppers. During the 2012 holiday season, many retailers saw a sharp increase in mobile sales, which accounted for a drastic rise in revenue. This year, retailers are expected to see a similar result, which will likely add further momentum to the mobile space going into 2014 .

\section{Mobile sales expected to reach $\$ 133$ billion by 2017}

According to the report from eMarketer, mobile commerce now accounts for a sizeable portion of the retail sales being recorded in the U.S. The report estimates that mobile sales will reach $\$ 41$ billion by the end of 2013, a 68\% increase over the level they had been in the previous year. By 2017, the report suggests that mobile sales will balloon to $\$ 133$ billion. Consumers appear to favour mobile commerce because of the convenience that it represents and it is becoming increasingly common for consumers to use their mobile devices to purchase products even when they are already in physical stores.

The report notes that tablets have become more popular for mobile commerce than smartphones. While smart phones may be more plentiful among consumers, tablets offer a better shopping experience. Larger screens offer better navigation capabilities and allow consumers to access sites that may not be optimized for viewing on a smartphone. The report notes that nine in 10 consumers are more willing to make a purchase with their tablet than with their smartphones.

\section{Report highlights the growth of mobile commerce in the UK}

A new report from IMRG, an e-commerce association based in the United Kingdom, and Capgemini, a business and technology consultancy firm, shows that mobile commerce is making strong progress in the United Kingdom. The report found that mobile commerce has seen exponential growth in the field of online retail over the last year, with the first quarter of 2013 showing impressive results. This may be due to the growing number of consumers with mobile devices, but could also be due to the new mobile commerce services that are emerging in the market.

\section{Mobile commerce new represents $20 \%$ of online sales}

According to the report, mobile commerce accounted for $20.2 \%$ of the online sales seen in the United Kingdom during the first quarter of 2013. This is an increase from the $15.4 \%$ of sales mobile commerce 
represented in the fourth quarter of 2012. The report shows that mobile traffic to retail sites has been growing quickly as more sites become optimized for use on mobile devices. These sites have also been seeing higher consumer engagement, which has been translated into strong sales.

The United Kingdom has become one of the most active markets in the world when it comes to mobile commerce. The country's retail sector has been especially aggressive in this field, hoping to engage consumers in a new way and appeal to their changing interests. Several retailers, such as Tesco, have been able to establish a strong foothold among consumers, offering comprehensive mobile commerce services that making shopping and purchasing online easier.

Mobile sales to continue to grow due to consumer behavior

Mobile commerce has not been showing any signs of slowing down in the foreseeable future. Since 2010, mobile commerce sales have grown in the United Kingdom by more than 5,000\% and are beginning to represent a significant economic force. As more consumers become interested in the field of mobile commerce, mobile sales will continue to show strong growth well into the future.

In this changing age of technology, companies need to continuously adapt their online strategies and tailor their shopping channels for the evolving digital consumer. With the iPhone offered by most major mobile carriers and the proliferation of other smart phones in the market.

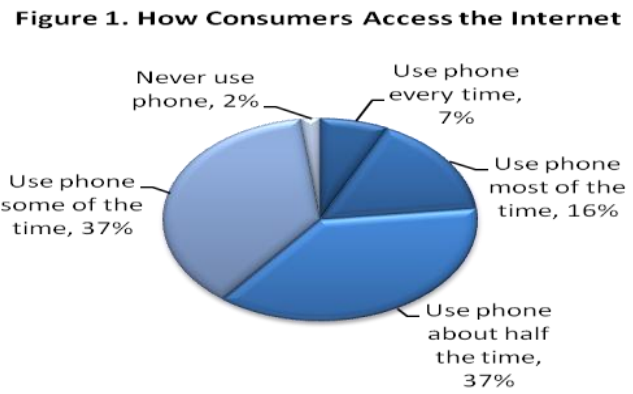

it is not surprising that a number of consumers already rely on their phones instead of their computers as their primary means of accessing the Internet. According to a recent consumer survey by Rockbridge, half (47\%) of online consumers own a smart phone with web access and a fourth (23\%) prefer to use their phone instead of a computer to go online "always" or "most of the time". Only $2 \%$ of smart phone consumers never use their phone to go online. (See Figure 1)

Consumers are doing more than just browsing or watching videos while on the mobile internet; they are using their device as a shopping aide. The vast majority of smart phone consumers have used their phone to search for better deals while in a store $(82 \%)$ or to visit a store's website while in their store $(72 \%)$. Over half $(58 \%)$ have received a coupon on their phone after sending a text message and half $(50 \%)$ used a coupon that was stored on their phone. Two-thirds (64\%) have paid for a product or service on their phone. (See Figure 2)

About this Study: Rockbridge surveyed 257 smart phone
owners from a national online panel. The results were
weighted to match demographic representation in the Census.
The margin of error on the findings reported here is plus or
minus 6 percentage points. Rockbridge is a custom market
research firm that specializes in technology and services.

In the future, smart phone consumers plan to increase some mobile internet activities when shopping. They will be more likely to store items such as coupons on their phones so that they can be used at stores or other businesses (50\% do this currently, with 77\% planning to in the future). Four-in-ten (38\%) have used a mobile ticket (e.g., a movie or sporting event) stored on their phone and another $21 \%$ plan to in the future. Consumers will also be more likely to scan a barcode with their phone (56\% vs. $70 \%$ in the future).

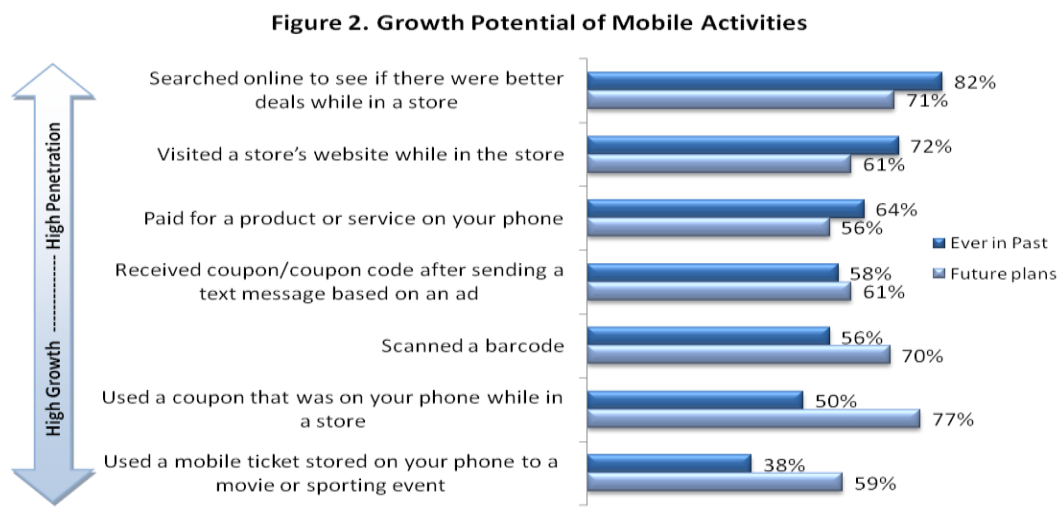


Some mobile internet shopping activities have reached their saturation point and appear to be ebbing, possibly because the previous experience was not satisfying or because consumers do not see a need for it. Notably, consumers will be less likely to use their phones while in the store to search for better online deals or to visit the store's website. Interestingly, the likelihood of consumers paying for a product or service on their phone will also decrease, from $64 \%$ currently to only $56 \%$ in the future. This will present some challenges to companies to make these activities more relevant and easier to accomplish on a mobile device.

The most common item currently purchased on smart phones consists of apps from the provider's app store, but more than a quarter have recently purchased something tangible, such as a new pair of shoes, which might have traditionally been bought online or in the store. (See Figure 3). Many of those who purchased something other than an app or phone content using their phone chose this method because it was more convenient $(46 \%)$ or because they were not around a computer (27\%). Since phones are used mainly when it is a matter of convenience, marketers should expect purchases to be made by the same customers in both mobile and stationary channels.

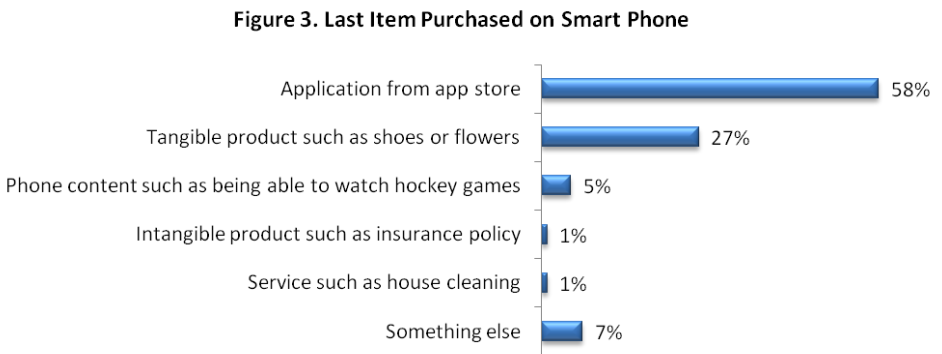

Many consumers have avoided purchasing on their mobile phones. One of the reasons is a diminished ability to see products in greater detail (28\%); therefore, zoom features on mobile sites may be useful in motivating consumers to purchase. Some also have concerns about the privacy of their personal information (22\%), so companies may need to consider modifying and updating methods used during Web 1.0 to reassure consumers that their information is protected.

M-commerce provides consumers more flexibility when accessing the internet and they are taking advantage of it now and plan to do so in the future. Mobile consumers are delving into new activities while avoiding others, and marketers will need to continue to innovate and provide user-friendly shopping experiences to attract these savvy consumers.

\section{Conclusion}

With the blast of smart phones, tablets, $3 \mathrm{G}$ services and the acceptance of unlimited data service plans, M-Commerce provides business owners the opportunity to easily connect with their customers in real time wherever and whenever they might be. We can finally conclude that M-Commerce is basically a benediction for everyone. No doubt, it too has some disadvantages and challenges, but one cannot deny from the benefits of MCommerce that has shortened the gaps between everyone.

\section{References}

[1]. M-commerce definition and Introduction from "Business, Entrepreneurship and Management" by C.B GUPTA, university of delhi.

[2]. Mobile Commerce: Technology, Theory, and Applications Brian Ernest Mennecke, Troy J. Strader Idea Group Inc (IGI), 2003

[3]. Mirzaie, Jahanshahi, Asadollahi, Mobile commerce beyond electronic commerce: issue and challenges,asian Journal of Business and Management Sciences.

[4]. Future Outlook of M-commerce from "Business, Entrepreneurship and Management" by C.B GUPTA, University of Delhi.

[5]. Future Outlook and growth of M-commerce http://www.mobile-financial.com/news/mobile-commerce-shows-strong-growththrough-2012

[6]. New report sheds light on the success being seen in mobile commerce http://www.mobilecommercepress.com/report-highlights-growth-mobilecommerce-sector/859224/

[7]. UK mobile commerce shows impressive growth http://www.mobilecommercepress.com/report-highlights-the-growth-of-mobile-commercein-the-uk/856811/

[8]. Growth analysis of m commerce http://www.rockresearch.com/online-marketers-beware-m-commerce-is-changing-your-game 